\section{Kidney \\ Blood Pressure Research}

\title{
Plasma Desphospho-Uncarboxylated Matrix Gla Protein as a Marker of Kidney Damage and Cardiovascular Risk in Advanced Stage of Chronic Kidney Disease
}

\author{
Ilona Kurnatowska ${ }^{\mathrm{a}}$ Piotr Grzelak ${ }^{\mathrm{b}} \quad$ Anna Masajtis-Zagajewska ${ }^{\mathrm{a}}$ \\ Magdalena Kaczmarska ${ }^{b} \quad$ Ludomir Stefańczyk $^{b}$ Cees Vermeer ${ }^{c}$ \\ Katarzyna Maresz ${ }^{\mathrm{d}}$ Michał Nowicki ${ }^{\mathrm{a}}$
}

aDepartment of Nephrology, Hypertension and Kidney Transplantation, bDepartment of Radiology and Diagnostic Imaging, Medical University of Łódź, Poland; 'R\&D Group VitaK, Maastricht University, Maastricht, The Netherlands; IInternational Science and Health Foundation, Cracow, Poland

\section{Key Words}

Dp-ucMGP • Chronic kidney disease $\cdot$ Vitamin K2

\begin{abstract}
Background/Aims: Desphospho-uncarboxylated matrix Gla protein (dp-ucMGP) is formed as a result of vitamin $\mathrm{K}$ insufficiency. The aim of this study was to investigate the association between plasma dp-ucMGP, kidney function and cardiovascular risk factors before and after 9-months substitution of vitamin K2 in non-dialysis patients with chronic kidney disease (CKD) stage 4 and 5. Methods: 38 CKD patients were supplemented for $270 \pm 12$ days with $90 \mu \mathrm{g}$ vitamin $\mathrm{K} 2$ and $10 \mu \mathrm{g}$ cholecalciferol or $10 \mu \mathrm{g}$ cholecalciferol alone. At baseline and at followup circulating calcium, phosphate, lipids, hemoglobin, albumin and total protein, dp-ucMGP, osteoprotegerin, fetuin A, osteocalcin and fibroblast grown factor 23 (FGF-23) were assessed. Proteinuria was assessed in the first morning void. Results: Baseline plasma dp-ucMGP was $1018.6 \pm 498.3 \mathrm{pmol} / \mathrm{l}$ and was significantly higher in patients at stage 5 CKD $(1388.3 \pm 505.4$ $\mathrm{pmol} / \mathrm{l})$ than at stage $4(885.1 \pm 419.7 \mathrm{pmol} / \mathrm{l}), \mathrm{p}=0.04$. Vitamin $\mathrm{K} 2$ supplementation resulted in a decrease of dp-ucMGP level by $10.7 \%$. Plasma dp-ucMGP was positively associated with proteinuria, serum creatinine, PTH and FGF-23; and inversely associated with glomerular filtration rate, serum hemoglobin and albumin. Conclusions: High dp-ucMGP level, reflecting a poor vitamin $\mathrm{K}$ status seems to be associated with kidney damage and may be also a marker of cardiovascular risk in CKD patients. Supplementation with vitamin K2 may improve the carboxylation status of MGP.




\section{Kidney Blood Pressure Research}

Kidney Blood Press Res 2016;41:231-239

DOI: 10.1159/000443426

Published online: April 21, 2016

(C) 2016 The Author(s). Published by S. Karger AG, Basel www.karger.com/kbr

\section{Introduction}

Vitamin $\mathrm{K}$ is a fat-soluble vitamin that occurs in two biologically active forms: phylloquinone (vitamin K1) and menaquinones (vitamin K2). The major dietary sources of vitamin K1 are leafy green vegetables and vegetable oils. The richest dietary sources of vitamin $\mathrm{K} 2$ are meat, eggs and fermented dairy like cheese and curd [1]. All these products, the former due to high content of potassium, and the latter due to high content of protein and phosphorus should be limited in chronic kidney disease (CKD) patients' diet. These dietary restrictions may explain why subclinical vitamin K deficiency is highly prevalent in CKD patients [2].

The majority of patients with CKD will die of a cardiovascular (CV) event before renal replacement therapy has been initiated [3]. The high rate of CV morbidity and mortality among CKD patients is related to both to traditional and nontraditional risk factors [4].

Several studies have reported the association between high vitamin K intake and lower $\mathrm{CV}$ risk $[5,6]$. The $\mathrm{CV}$ protective effects of vitamin $\mathrm{K} 2$ may be associated with the inhibition of arterial calcification, atherosclerosis and arterial stiffening [5-8]. Both vitamins K1 and K2 catalyze the gammaglutamate carboxylation of all vitamin K-dependent proteins. However, vitamin $\mathrm{K} 1$ is predominantly transported to the liver and mediates in the maturation of several blood coagulation factors, while vitamin K2 has a more widespread tissue distribution and is thus more specifically involved in the carboxylation of matrix Gla protein (MGP) [9]. MGP is a powerful inhibitor of vascular calcification [10]. In case of vitamin K deficiency, MGP is not carboxylated and undercarboxylated MGP predominantly accumulates in areas of intimal and medial calcification [11]. In an experimental animal model, high vitamin K2 intake has been shown to even reverse pre-existing medial calcifications [12]. MGP exists as various forms, which differ in their state of phosphorylation and/or carboxylation: phosphorylated (pMGP) nonphosphorylated (dephospho-MGP, dpMGP), carboxylated (cMGP) or uncarboxylated (ucMGP). Development of the methods to measure circulating MGP species have enabled their diagnostic utility [13]. The plasma desphospho-ucMGP (dpucMGP) fraction is considered as a marker of vascular vitamin $\mathrm{K}$ status and a risk marker for CV morbidity and mortality [14]. The vitamin K insufficiency established in the majority of hemodialysis (HD) [15] and advanced CKD patients [2] may contribute to their strongly increased CV risk. Consistently, randomized placebo-controlled trials showed a significant reduction of plasma dp-ucMGP levels after supplementation with menaquinone in healthy postmenopausal women [8] and in HD patients [16].

The aim of this study was to investigate the association of plasma dp-ucMGP concentrations with kidney function and traditional and non-traditional risk factors of CV diseases before and after 270 days substitution of menaquinone in non-dialysis patients with CKD stage 4 and 5.

\section{Material and Methods}

The study was prospective, randomized and double-blinded. All patients gave their informed, written consent. The 38 patients who fulfilled the inclusion and exclusion criteria were included in the present analysis (Figure 1).

The inclusion criteria were as follows: age 18 to 70 years old, with a confirmed diagnosis of CKD stage 4-5 (defined as having a stable estimated glomerular filtration rate (eGFR) $<30 \mathrm{ml} / \mathrm{min} /$ per $1.73 \mathrm{~m}^{2}$ over at least 6 months, not yet requiring dialysis, and having a coronary calcification score (CACS) of $\geq 10$ Agatston units (A.u.). The exclusion criteria were a history of major CV complications (myocardial infarction, clinically significant arrhythmia including atrial fibrillation, congestive heart failure, stroke, peripheral vascular disease), a history of thrombosis or coagulation disorders, treatment with oral anticoagulants, steroid and other hormonal therapies, and treatment with vitamin D or its analogs.

All enrolled patients were non-smoking Caucasians (21 men, mean age $60 \pm 3.0 \mathrm{yrs}$. and 17 women, mean age $56 \pm 1.5$ yrs.), all were receiving statins due to hyperlipidemia, and had well-controlled hypertension.

The causes of renal failure were chronic glomerulonephritis in 15 cases, diabetic nephropathy in 7 , 


\section{Kidney Blood Pressure Research}

Kidney Blood Press Res 2016;41:231-239

DOI: 10.1159/000443426

Published online: April 21, 2016

(C) 2016 The Author(s). Published by S. Karger AG, Base www.karger.com/kbr

Kurnatowska/Grzelak/Masajtis-Zagajewska/Kaczmarska/Stefańczyk/Vermeer/Maresz/Nowicki: Plasma Desphospho-Uncarboxylated Matrix Gla Protein and Chronic Kidney Disease

Assessed for eligibility: 75 consecutive patients with 3 to 5 stages of CKD

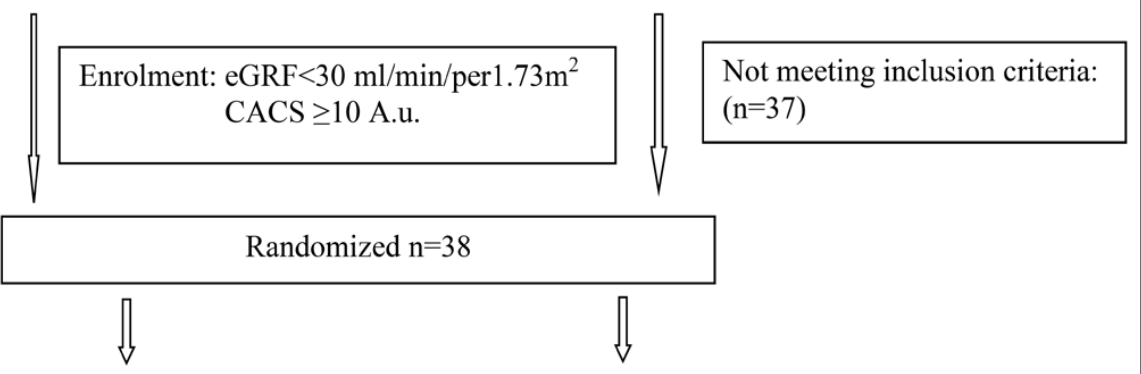

Allocated to treatment group $\mathrm{K}+\mathrm{D}(\mathrm{n}=26)$ :

$90 \mu \mathrm{g}$ vitamin $\mathrm{K}_{2}+10 \mu \mathrm{g}$ cholecalciferol

Allocated to treatment group D $(n=12)$ :

$10 \mu \mathrm{g}$ cholecalciferol

Treatment period: ( $270 \pm 12$ days $)$
A.u.: Agatston units
CKD: chronic kidney disease
CACS: coronary artery calcification score

Fig. 1. Schematic illustration of patient selection and randomization and study design.

polycystic kidney disease in 4, hypertensive nephropathy in 5, tubulointerstitial nephritis in 2 , and unknown in 5 patients.

The randomization cards were prepared on the assumption that twice the number of patients would be treated with both vitamins: $K 2$ and $D(n=26$; vitamin $K+D$ group), than $D$ alone ( $n=12$; vitamin $\mathrm{D}$ group; active vs control group). The patients in group $\mathrm{K}+\mathrm{D}$ received an oral dose of $90 \mu \mathrm{g}$ of vitamin $\mathrm{K} 2$ (menaquinone-7, MK-7) plus $10 \mu \mathrm{g}$ cholecalciferol per day for $270 \pm 12$ days; those in group D received $10 \mu \mathrm{g}$ cholecalciferol alone. Tablets containing vitamin $\mathrm{K} 2+\mathrm{D}$ or vitamin D were identical in size and appearance (both kinds of tablets were prepared by NattoPharma, Høvik, Norway). Anthropometric measurements were performed and fasting blood and urine samples for biochemical, morphological and coagulation tests were obtained at the time of randomization and at end of treatment and were measured with routine laboratory methods. Serum and plasma samples were prepared after standard centrifugation and frozen at $-80^{\circ} \mathrm{C}$ until measurements.

Circulating total MGP was measured using a sandwich ELISA (USCN Life Science Inc, www.uscnk. com), plasma dp-ucMGP was assessed using the inaKtif MGP iSYS kit (Immunodiagnostic Systems; www. idsplc), which is a dual-antibody test based on the previously described sandwich ELISA (developed by VitaK, Maastricht University, The Netherlands), serum osteoprotegerin (OPG) by ELISA (Immunodiagnostic Systems; www.idsplc), serum fetuin A by ELISA (Epitope Diagnostics,Inc., www.epitopediagnostics.com), serum 25-hydroxyvitamin D (250HD) by radioimmunoassay (IBL International; www.IBL-International. com), serum high sensitive CRP by ELISA (IBL International; www.IBL-International.com), plasma FGF-23 was determined using a human FGF-23 ELISA kit (Immutopics, www.immutopicsintl.com).

The study protocol was approved by the local Ethics Committee and was performed in accordance with the ethical principles of Declaration of Helsinki.

\section{Statistical analysis}

The results are presented as mean \pm SD. A $\chi^{2}$ test was used for sex comparison. The Shapiro-Wilk test was used to confirm the normality of the distribution. For normal distributions, the Student's T test for unpaired data was used to assess the significance of the differences between the means, and a Bonferroni correction was applied for multiple comparisons. Pearson's linear regression equations were used to determine the power of association between continuous variables, while Spearman's rank correlation coefficient was calculated for non-normally distributed parameters. Depending on the data distribution, the comparison of follow-up data $v s$ baseline was performed using the $t$-test for dependent variables or Wilcoxon 


\section{Kidney Blood Pressure Research}

Kurnatowska/Grzelak/Masajtis-Zagajewska/Kaczmarska/Stefańczyk/Vermeer/Maresz/Nowicki: Plasma Desphospho-Uncarboxylated Matrix Gla Protein and Chronic Kidney Disease

Table 1. Anthropometric and laboratory parameters at baseline and after 270 days of treatment with vitamin $\mathrm{K} 2+\mathrm{D}(\mathrm{K}+\mathrm{D}$ group) or vitamin $\mathrm{D}$ alone (D group)

\begin{tabular}{|c|c|c|c|c|c|c|c|}
\hline \multirow[t]{2}{*}{ Parameter } & \multirow{2}{*}{$\begin{array}{c}\text { Baseline } \\
\text { Total cohort } \\
(n=38)\end{array}$} & \multicolumn{2}{|c|}{ Follow-up } & \multicolumn{4}{|c|}{$\begin{array}{l}\text { Absolute changes from } \\
\text { baseline }\end{array}$} \\
\hline & & $\begin{array}{c}\text { Vitamin } \mathrm{K}+\mathrm{D} \\
(\mathrm{N}=26)\end{array}$ & $\begin{array}{c}\text { Vitamin D } \\
(\mathrm{N}=12)\end{array}$ & $p$-value & $\begin{array}{l}\text { Vitamin } K+D \\
(N=26)\end{array}$ & $\begin{array}{l}\text { Vitamin D } \\
(\mathrm{N}=12)\end{array}$ & $p$-value \\
\hline Gender (male) & $21(55.3 \%)$ & $14(53.8 \%)$ & $7(58.3 \%)$ & 0.5 & & & \\
\hline Age, yrs & $58.6 \pm 11.2$ & $59.4 \pm 9.6$ & $55.4 \pm 15.2$ & 0.07 & & & \\
\hline BMI $\left(\mathrm{kg} / \mathrm{m}^{2}\right)$ & $29.8 \pm 4.7$ & $29.8 \pm 4.1$ & $28.5 \pm 4.9$ & 0.4 & $-0.5 \pm 4.3$ & $-0.2 \pm 5.1$ & 0.4 \\
\hline eGFR (ml/min/1.73m²) & $24.2 \pm 8.2$ & $18.4 \pm 11.2$ & $22.0 \pm 10.8$ & 0.06 & $-1.6 \pm 5.6$ & $-0.2 \pm 2.4$ & 0.4 \\
\hline Serum creatinine (mg/dl) & $3.04 \pm 1.3$ & $4.2 \pm 2.7$ & $2.6 \pm 0.9$ & 0.02 & $0.84 \pm 1.65$ & $0.06 \pm 0.2$ & 0.3 \\
\hline Uric acid (mg/dl) & $7.4 \pm 1.7$ & $6.5 \pm 1.3$ & $7.9 \pm 1.2$ & 0.05 & $-0.34 \pm 1.2$ & $-0.6 \pm 1.3$ & 0.6 \\
\hline Total Cholesterol (mg/dl) & $194.9 \pm 59.2$ & $218.3 \pm 55$ & $185.7 \pm 43.2$ & 0.2 & $7.2 \pm 61.4$ & $18.1 \pm 27.3$ & 0.4 \\
\hline Triglyceride $(\mathrm{mg} / \mathrm{dl})$ & $186.7 \pm 101.0$ & $197 \pm 115$ & $147.8 \pm 42$ & 0.3 & $-16.9 \pm 101.0$ & $9.09 \pm 46.1$ & 0.4 \\
\hline LDL (mg/dl) & $111.8 \pm 42.6$ & $125.5 \pm 47.3$ & $109 \pm 32.1$ & 0.4 & $5.7 \pm 62.9$ & $10.5 \pm 16.3$ & 0.8 \\
\hline HDL (mg/dl) & $49.8 \pm 17.6$ & $57.2 \pm 28.1$ & $52.3 \pm 11.2$ & 0.4 & $3.9 \pm 24.7$ & $4.9 \pm 6.6$ & 0.2 \\
\hline Calcium (mmol/l) & $2.4 \pm 0.1$ & $2.4 \pm 0.2$ & $2.5 \pm 0.2$ & 0.1 & $-0.02 \pm 0.14$ & $0.05 \pm 0.13$ & 0.2 \\
\hline Phosphate (mmol/l) & $1.3 \pm 0.4$ & $1.5 \pm 0.6$ & $1.2 \pm 0.2$ & 0.1 & $0.17 \pm 0.5$ & $0.13 \pm 0.12$ & 0.3 \\
\hline $\mathrm{Ca} \times \mathrm{P}\left(\mathrm{mmol}^{2} / \mathrm{l}^{2}\right)$ & $3.1 \pm 1.0$ & $3.7 \pm 1.5$ & $3.0 \pm 0.6$ & 0.2 & $0.36 \pm 1.05$ & $0.37 \pm 0.3$ & 0.1 \\
\hline PTH $(\mathrm{pg} / \mathrm{ml})$ & $173.0 \pm 126.7$ & $235 \pm 245.1$ & $120.4 \pm 61.4$ & 0.2 & $37.5 \pm 189.7$ & $-13.2 \pm 63.6$ & 0.9 \\
\hline Hemoglobin $(\mathrm{g} / \mathrm{l})$ & $12.3 \pm 1.6$ & $11.4 \pm 1.9$ & $13.7 \pm 1.8$ & 0.001 & $-5.2 \pm 24.4$ & $17.1 \pm 37.2$ & 0.02 \\
\hline Albumin (mg/dl) & $41.3 \pm 3.1$ & $40.6 \pm 3.2$ & $42.3 \pm 2.2$ & 0.07 & $-0.04 \pm 3.6$ & $-0.05 \pm 2.8$ & 0.9 \\
\hline Total protein (mg/dl) & $71.2 \pm 3.1$ & $69.1 \pm 8.2$ & $70.8 \pm 1.5$ & 0.9 & $-1.6 \pm 7.7$ & $-0.6 \pm 3.2$ & 0.8 \\
\hline Proteinuria g/l & $0.75 \pm 0.9$ & $0.9 \pm 1.08$ & $0.35 \pm 0.4$ & 0.08 & $-0.12 \pm 0.25$ & $0.09 \pm 0.5$ & 0.2 \\
\hline Prothrombin time * & $13.1 \pm 0.4$ & $12.9 \pm 0.6$ & $13.0 \pm 0.4$ & 0.9 & $-0.3 \pm 0.5$ & $-0.1 \pm 0.4$ & 0.6 \\
\hline 250HD (ng/ml) & $22.0 \pm 10.8$ & $32.0 \pm 12.1$ & $33.4 \pm 11.7$ & 0.8 & $11.4 \pm 11.9$ & $8.6 \pm 9.7$ & 0.6 \\
\hline dp-ucMGP (pmol/l) & $1018.6 \pm 498.3$ & $961.5 \pm 506.7$ & $820.7 \pm 565.2$ & 0.5 & $-115.6 \pm 234.5$ & $26.8 \pm 206.2$ & 0.12 \\
\hline FGF-23 (pg/ml) & $33.2 \pm 99.7$ & $72.5 \pm 165$ & $13.3 \pm 8.4$ & 0.3 & $30.2 \pm 140.5$ & $-3.3 \pm 11.7$ & 0.1 \\
\hline $\mathrm{OC}(\mathrm{ng} / \mathrm{ml})$ & $55.5 \pm 52.3$ & $53.5 \pm 41.0$ & $58 \pm 43$ & 0.9 & $-6.8 \pm 38.8$ & $17.2 \pm 22.7$ & 0.02 \\
\hline OPG (pg/ml) & $5.4 \pm 2.1$ & $6.5 \pm 2.1$ & $5.1 \pm 1.7$ & 0.1 & $0.5 \pm 1.6$ & $0.4 \pm 0.7$ & 0.9 \\
\hline Fetuin A (ng/ml) & $110.6 \pm 40.0$ & $111.4 \pm 35$ & $122.4 \pm 30.8$ & 0.6 & $2.0 \pm 54.3$ & $9.7 \pm 38.5$ & 0.9 \\
\hline $\mathrm{hsCRP}(\mu \mathrm{g} / \mathrm{ml})$ & $5.9 \pm 4.8$ & $7.8 \pm 5.2$ & $6.9 \pm 5.6$ & 0.6 & $1.4 \pm 5.2$ & $2.4 \pm 4.2$ & 0.4 \\
\hline
\end{tabular}

test, respectively. The Wilcoxon test was used to compare the results before and after the treatment in the same group, and the Mann-Whitney U test to compare the results between two treated groups. The level of statistical significance was set at $\mathrm{p}<0.05$.

\section{Results}

Participants were in 4 stage of CKD ( $\mathrm{n}=27$, mean eGFR $24.2 \pm 6.6 \mathrm{ml} / \mathrm{min} / 1.73 \mathrm{~m}^{2}$ ) or in 5 CKD stage $\left(\mathrm{n}=11\right.$, mean eGFR $\left.11.2 \pm 3.2 \mathrm{ml} / \mathrm{min} / 1.73 \mathrm{~m}^{2}\right)$. The patients randomized to the vitamin $\mathrm{K}+\mathrm{D}$ group demonstrated a lower baseline estimated glomerular filtration rate (eGFR) $19.1 \pm 10.1 \mathrm{ml} / \mathrm{min} / 1.73 \mathrm{~m}^{2}$ than those in group D: $25.3 \pm 6.6 \mathrm{ml} / \mathrm{min} / 1.73 \mathrm{~m}^{2}, \mathrm{p}<0.02$. The kidney function did not change significantly after vitamins substitution (Table 1).

In a cross-sectional baseline assessment the mean plasma level of dp-ucMGP was $1018.6 \pm 498.3 \mathrm{pmol} / \mathrm{l}$ and was significantly higher in patients with 5 stage of CKD (1388.3 $\pm 505.4 \mathrm{pmol} / \mathrm{l})$ than with 4 stage $(885.1 \pm 419.7 \mathrm{pmol} / \mathrm{l}), \mathrm{p}=0.04$. The baseline and followup anthropometric and laboratory parameters and their changes after the vitamins supplementation are presented in Table 1.

After $270 \pm 12$ days of vitamins supplementation, a significant decrease of dp-ucMGP level was observed in vitamin $\mathrm{K}+\mathrm{D}$ group , in vitamin $\mathrm{D}$ group it did not change (Figure 2). Vitamin K2 supplementation resulted in a decrease of dp-ucMGP level by $10.7 \%$ (in $70.2 \%$ of patients taking vitamin K2 the decrease of dp-ucMGP level was observed).

At baseline, in all patients, a strong inverse association between eGFR and dp-MGP was observed (Table 2; Figure 3). This negative correlation was confirmed after $270 \pm 12$ days 


\section{Kidney Blood Pressure Research}

Kidney Blood Press Res 2016;41:231-239

DOI: 10.1159/000443426

Published online: April 21, 2016

(C) 2016 The Author(s). Published by S. Karger AG, Base www.karger.com/kbr

of vitamins supplementation (Table 2). A positive correlation was observed between serum creatinine and plasma dp-ucMGP level both baseline and after vitamins supplementation (Table 2).

Patients with the higher level of serum albumin had lower level of dpucMGP both before and after vitamin $\mathrm{K}$ supplementation. Furthermore, the dp-ucMPG positively correlated with proteinuria in a morning urine sample. Patients with lower hemoglobin level had higher level of dp-ucMGP at baseline and the same correlation was observed in follow-up. The positive correlation

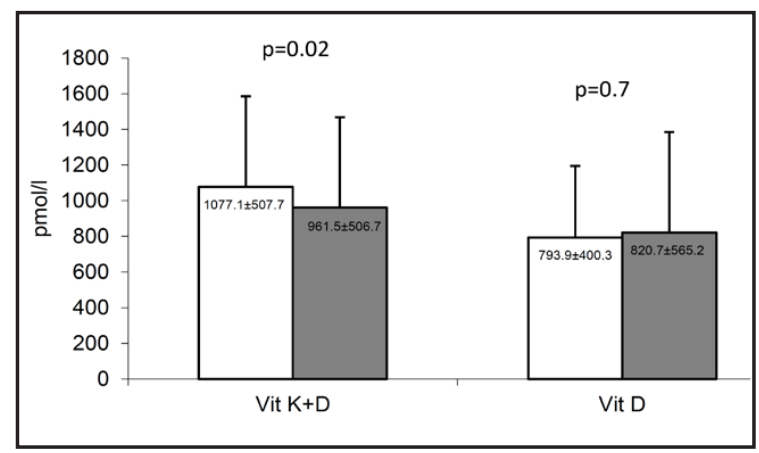

Fig. 2. Circulating desphospho-uncarboxylated matrix Gla protein (dp-ucMGP) at baseline and after 270 days of vitamin $\mathrm{K} 2+\mathrm{D}(\mathrm{K}+\mathrm{D}$ group) or vitamin $\mathrm{D}$ alone (D group) substitution

Table 2. Associations between dp-ucMGP levels and demographic and laboratory variables at baseline and in follow-up

\begin{tabular}{|c|c|c|c|c|c|c|c|c|}
\hline \multirow[t]{2}{*}{ Variables } & \multicolumn{2}{|c|}{$\begin{array}{c}\text { Baseline } \\
\text { All }(\mathrm{N}=38)\end{array}$} & \multicolumn{2}{|c|}{$\begin{array}{l}\text { Follow-up } \\
\text { All }(\mathrm{N}=38)\end{array}$} & \multicolumn{2}{|c|}{$\begin{array}{c}\text { Follow-up } \\
\text { Vitamin } \mathrm{K}+\mathrm{D} \\
(\mathrm{N}=26)\end{array}$} & \multicolumn{2}{|c|}{$\begin{array}{c}\text { Follow-up } \\
\text { VitaminD } \\
(\mathrm{N}=12)\end{array}$} \\
\hline & $\mathrm{R}$ & $p$ & $\mathrm{r}$ & $p$ & $\mathrm{r}$ & $p$ & $\mathrm{r}$ & $p$ \\
\hline Gender (male) & -0.27 & 0.13 & -0.44 & 0.20 & -0.41 & 0.06 & -0.47 & 0.47 \\
\hline Age, yrs & -0.11 & 0.74 & 0.20 & 0.74 & 0.21 & 0.16 & -0.32 & 0.36 \\
\hline BMI $\left(\mathrm{kg} / \mathrm{m}^{2}\right)$ & -0.10 & 0.85 & -0.11 & 0.80 & 0.14 & 0.41 & -0.67 & 0.06 \\
\hline eGFR (ml/min/1.73 m²) & -0.50 & 0.001 & -0.57 & 0.001 & -0.55 & 0.004 & -0.67 & 0.05 \\
\hline Serum creatinine (mg/dl) & 0.41 & 0.001 & 0.41 & 0.003 & 0.38 & 0.007 & 0.85 & 0.05 \\
\hline Uric acid (mg/dl) & -0.04 & 0.81 & -0.09 & 0.40 & -0.12 & 0.61 & 0.29 & 0.49 \\
\hline Total Cholesterol (mg/dl) & 0.33 & 0.47 & 0.16 & 0.77 & 0.23 & 0.73 & 0.038 & 0.73 \\
\hline Triglyceride $(\mathrm{mg} / \mathrm{dl})$ & 0.26 & 0.55 & $-0 ., 01$ & 0.87 & -0.11 & 0.76 & -0.22 & 1.00 \\
\hline LDL $(\mathrm{mg} / \mathrm{dl})$ & 0.25 & 0.48 & 0.24 & 0.59 & 0.25 & 0.92 & 0.52 & 0.09 \\
\hline $\mathrm{HDL}(\mathrm{mg} / \mathrm{dl})$ & 0.26 & 0.57 & 0.07 & 0.99 & 0.13 & 0.81 & -0.13 & 0.77 \\
\hline Calcium (mmol/l) & -0.19 & 0.2 & -0.39 & 0.06 & -0.44 & 0.08 & -0.05 & 0.89 \\
\hline Phosphate (mmol/l) & 0.25 & 0.10 & 0.39 & 0.002 & 0.42 & 0.001 & -0.08 & 0.39 \\
\hline $\mathrm{Ca} \times \mathrm{P}\left(\mathrm{mmol}^{2} / \mathrm{l}^{2}\right)$ & 0.21 & 0.17 & 0.33 & 0.01 & 0.35 & 0.01 & -0.09 & 0.38 \\
\hline PTH $(\mathrm{pg} / \mathrm{ml})$ & 0.34 & 0.01 & 0.45 & 0.001 & 0.45 & 0.004 & 0.60 & 0.05 \\
\hline Hemoglobin $(\mathrm{g} / \mathrm{l})$ & -0.59 & 0.001 & -0.51 & 0.002 & -0.49 & 0.01 & -0.61 & 0.05 \\
\hline Albumin (mg/dl) & -0.45 & 0.03 & -0.41 & 0.01 & -0.46 & 0.03 & -0.19 & 0.06 \\
\hline Total protein (mg/dl) & -0.25 & 0.40 & -0.09 & 0.29 & -0.11 & 0.24 & -0.03 & 1.00 \\
\hline Proteinuria g/l & 0.38 & 0.03 & 0.35 & 0.05 & 0.42 & 0.04 & 0.68 & 0.04 \\
\hline Prothrombin time (sec) & 0.05 & 0.73 & 0.18 & 0.56 & 0.24 & 0.38 & 0.29 & 0.94 \\
\hline $250 \mathrm{HD}(\mathrm{ng} / \mathrm{ml})$ & -0.39 & 0.04 & -0.21 & 0.21 & -0.29 & 0.20 & -0.41 & 0.19 \\
\hline MGP $(\mathrm{pg} / \mathrm{ml})$ & 0.12 & 0.52 & -0.13 & 0.50 & -0.01 & 0.95 & 0.09 & 0.52 \\
\hline FGF-23 (pg/ml) & 0.05 & 0.006 & 0.21 & 0.03 & 0.22 & 0.01 & 0.21 & 0.79 \\
\hline $\mathrm{OC}(\mathrm{ng} / \mathrm{ml})$ & 0.47 & 0.20 & 0.49 & 0.08 & 0.44 & 0.22 & 0.79 & 0.06 \\
\hline $\mathrm{OPG}(\mathrm{pg} / \mathrm{ml})$ & -0.05 & 0.41 & 0.24 & 0.13 & -0.09 & 0.82 & 0.36 & 0.52 \\
\hline Fetuin A (ng/ml) & -0.12 & 0.59 & -0.01 & 0.95 & -0.30 & 0.24 & 0.33 & 0.47 \\
\hline hsCRP $(\mu \mathrm{g} / \mathrm{ml})$ & -0.11 & 0.88 & -0.13 & 0.71 & 0.00 & 0.72 & -0.51 & 0.26 \\
\hline
\end{tabular}

BMI: body mass index; HDL: high density lipoprotein; LDL: low density lipoprotein; CaxP: calciumphosphorus product; 250HD: 25-hydroxyvitamin D; MGP: matrix Gla protein; OC: osteocalcin; OPG: osteoprotegerin; CRP: C-reactive protein; FGF-23: fibroblast growth factor 23

between parathyroid hormone and dp-ucMGP at baseline cross sectionally and in followup was noted. The same relationships were noted between dp-ucMGP and FGF-23 levels. The positive relationship between plasma dp-ucMGP level and phosphorous serum level and calcium x phosphorus index was noted only after vitamins supplementation. We did not observe any correlation between serum lipids and dp-ucMGP level and also between 


\section{Kidney Blood Pressure Research}

Kidney Blood Press Res 2016;41:231-239

\begin{tabular}{l|l}
\hline DOI: $10.1159 / 000443426$ & (C) 2016 The Author(s). Published by S. Karger AG, Basel
\end{tabular}

Published online: April 21, 2016

www.karger.com/kb

Kurnatowska/Grzelak/Masajtis-Zagajewska/Kaczmarska/Stefańczyk/Vermeer/Maresz/Nowicki: Plasma Desphospho-Uncarboxylated Matrix Gla Protein and Chronic Kidney Disease
dp-ucMGP plasma level and age or BMI. The correlations found both at baseline and after vitamins supplementation are shown in Table 2.

In a stepwise multivariate linear regression analysis including all variables, performed at baseline, hemoglobin, OPG, albumin, triglyceride, LDL-cholesterol levels and eGFR were found to be independent determinants of the $\mathrm{dp}$ ucMGP level (Table 3).

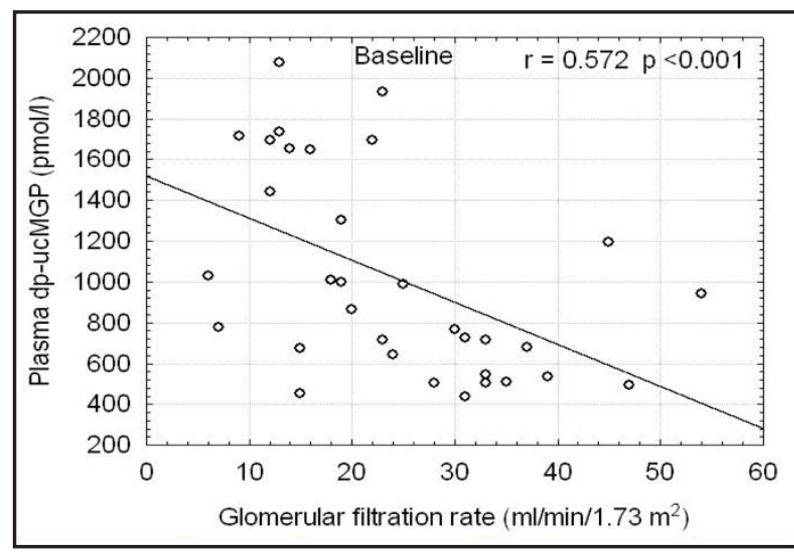

Fig. 3. The association between glomerular filtration rate and plasma dp-ucMGP levels at baseline.

Table 3. Variables associated with the dp-ucMGP levels in a stepwise multivariate linear regression analysis

\begin{tabular}{lccccc}
\hline Variable & $\beta$ & $\mathrm{B} \pm$ SEM & $\mathrm{B}$ & $\mathrm{B} \pm$ SEM & $p$ \\
\hline Hamoglobin $(\mathrm{g} / \mathrm{l})$ & -0.440911 & 0.144566 & -144.529 & 47,3884 & 0.006 \\
Osteoprotegerin $(\mathrm{pg} / \mathrm{ml})$ & -0.579735 & 0.129394 & $-136,392$ & 30.4421 & 0.000 \\
Albumin $(\mathrm{mg} / \mathrm{dl})$ & -0.360981 & 0.125311 & -55.178 & 19.1546 & 0.009 \\
eGFR $\left(\mathrm{ml} / \mathrm{min} / 1.73 \mathrm{~m}^{2}\right)$ & -0.236297 & 0.117226 & -3.447 & 1.7099 & 0.005 \\
Triglyceride $(\mathrm{mg} / \mathrm{dl})$ & 0.464845 & 0.161587 & 2.395 & 0.8324 & 0.001 \\
LDL-cholesterol $(\mathrm{mg} / \mathrm{dl})$ & -0.390898 & 0.182911 & -4.460 & 2.0871 & 0.044 \\
\hline
\end{tabular}

\section{Discussion}

In a previous study showed that lower vitamin $\mathrm{K}$ intake in CKD patients associated with increased dp-ucMGP level which reflects vascular vitamin K insufficiency [17-19]. Our data confirmed high plasma dp-ucMGP levels in advanced non-dialysis CKD patients when compared with the levels measured in healthy subjects $[20,21]$, whereas they were lower than those in previously reported in HD populations $[16,22,23]$. In the present study we showed a strong inverse association between kidney function assessed by eGFR and plasma dp-ucMGP concentrations in non-dialysis patients with CKD stage 4-5. A positive association was found between serum creatinine and plasma dp-ucMGP. Using stepwise multivariate linear regression analysis, eGFR was identified as an independent determinant of circulating dp-ucMGP. Our data are consistent with a recent observation that CKD patients are at risk of vitamin K deficiency [2] and show impaired MGP carboxylation status [16, 17]. We confirmed that also blood hemoglobin was associated with plasma dp-ucMGP, a fact that has been reported previously by Schurgers et al. in CKD population [17] and may be explained by assuming that anemia develops together with loss of kidney function [24].

Our study has shown a positive association between dp-ucMGP plasma level and proteinuria in morning urine from patients with advanced CKD. A similar observation was made by Boxma et al. in kidney transplant recipients [25]. Proteinuria and eGFR reduction are important and early markers of kidney damage and cardiovascular complications [24]. Boxma et al. also noticed that dp-ucMGP levels depended on factors other than vitamin $\mathrm{K}$ intake including renal function or use of vitamin $\mathrm{K}$ antagonists [25]. In our study we therefore excluded patients using vitamin K antagonists. Moreover, our data showed that supplementation with vitamin K2 significantly decreased the circulating dp-ucMGP levels and confirm previous observations about dose-dependent reduction of dp-ucMGP level in HD patients supplemented with menaquinone [16, 22]. 


\section{Kidney Blood Pressure Research}

Kidney Blood Press Res 2016;41:231-239

DOI: 10.1159/000443426

Published online: April 21, 2016

(C) 2016 The Author(s). Published by S. Karger AG, Basel www.karger.com/kbr

Our findings demonstrate an association between plasma dp-ucMGP levels and commonly used kidney damage markers. One explanation is that kidney damage is a major determinant of vascular vitamin $\mathrm{K}$ deficiency. On the other hand it seems also possible that poor vitamin K status is a risk factor for kidney dysfunction. In that line, kidney damage would not be a determinant for vitamin K status, but poor vitamin $\mathrm{K}$ status would be a risk factor for developing kidney disease. In theory, poor vitamin K status comes first, and results in an increased tendency of calcium deposition (not restricted to the vessels), stone formation and decreased kidney function. Additional research is needed to distinguish between both mechanisms.

Our findings also demonstrated an association between plasma dp-ucMGP and serum PTH levels in non-dialysis patients in CKD stage 4 and 5. This association was observed both at baseline and after 270-days of vitamin supplementation. Westenfeld et al. did not find a relationship between dp-ucMGP and mineral disturbances in the HD population [16], but in these patients there are additional factors which may influence PTH levels than in non-dialyzed CKD patients. In experimental studies it was shown that PTH induced MGP expression, and it was postulated that this induction may be critical for the inhibition of osteoblast mineralization [26,27]. Our observations may be relevant for this explanation because secondary hyperparathyroidism is one of the non-traditional risk factors of CV complications in CKD [28]. The association between mineral disturbances and dp-ucMGP may confirm the positive association between dp-ucMGP and FGF-23 level in our patients, both at baseline and in follow-up. A similar association was recently reported in HD patients [23]. Consistently, we found higher levels of dp-ucMGP in subjects with higher circulating levels of phosphate and higher phosphate-calcium index in the total group of participants even after vitamin $\mathrm{K}$ treatment.

Our study also showed that CKD patients with higher serum albumin levels had lower dp-ucMGP plasma concentrations; albumin level is one of the factors affecting dp-ucMGP in the stepwise multivariate linear regression analysis. This association was reported recently also by Delanaye et al. [23] and suggests that CKD patients in better general and nutritional status are at lower CV risk.

In our study population we did not observe associations between dp-ucMGP level and traditional CV risk factors such as age, BMI, serum lipids, but in a stepwise multivariate linear regression analysis triglyceride and LDL-cholesterol independently associated with plasma dp-ucMGP. The limited evidence from human studies suggests that high menaquinone intake may improve the blood lipid profile [29]. Our study showed that 270-days of vitamin K2 supplementation did not affect blood lipids. It should be emphasized that all our patients were chronically treated with statins due to hyperlipidemia. Likewise, Dalmeijer et al. did not observe any changes in lipid profile during vitamin K2 supplementation among healthy men and postmenopausal women [20]. Dam et al. recently reported that high intake of menaquinone was associated with lower incidence of metabolic syndrome and showed an association between triglycerides and dp-ucMGP concentrations [21].

Considering the strict correlations between commonly known CV risk factors like decreased eGFR and proteinuria and nontraditional factors like PTH, FGF-23, serum phosphate and calcium-phosphate index which were noted in our study and taking into account observations from other studies we conclude that dp-ucMGP may be a novel, surrogate marker of CV risk in CKD patients.

The limitation of our study is its small sample size with a consequent weak power of the statistical tests. Additionally, our CKD population was characterized by quite high scattering of same data, which could explain the high standard deviations of the means. Further, we could not exclude the impact of kidney function, which was worse in $\mathrm{K}+\mathrm{D}$ group than in $\mathrm{D}$ patients, on our final results. Lack of a control, healthy group is an additional weakness of our analysis. Another important limitation is that we assessed proteinuria only based on an early morning urine sample analysis; data for 24-hr albumin excretion or urine albumin-tocreatinine ratio (ACR), which are more reliable variables to evaluate albuminuria, were not available. The lack of an assessment of dietary intake of vitamin $\mathrm{K} 1$ and $\mathrm{K} 2$ is the another limitation. Furthermore, we did not account for menaquinones produced by microbiota in the intestine. 


\section{Kidney Blood Pressure Research}

Kidney Blood Press Res 2016;41:231-239

DOI: $10.1159 / 000443426$

Published online: April 21, 2016

(C) 2016 The Author(s). Published by S. Karger AG, Base

www.karger.com/kbr

Kurnatowska/Grzelak/Masajtis-Zagajewska/Kaczmarska/Stefańczyk/Vermeer/Maresz/Nowicki: Plasma Desphospho-Uncarboxylated Matrix Gla Protein and Chronic Kidney Disease

\section{Conclusions}

High dp-ucMGP level, reflecting a poor vitamin K status seems to be associated with kidney damage and may be also a marker of cardiovascular risk in CKD patients. Oral supplementation of vitamin K2 may improve the carboxylation status of vitamin K-dependent proteins in non-dialyzed CKD patients, but its potential clinical benefit remains to be proven.

\section{Disclosure Statement}

The authors of this manuscript state that they do not have any conflict of interests and nothing to disclose.

\section{Acknowledgements}

The authors gratefully acknowledge Hogne Vik, MD, PhD (CEO, NattoPharma, Norway) for supplying MenaQ7, and for preparation of the vitamin K2+cholecalciferol and cholecalciferol alone tablets, as well as immunodiagnostic Systems (IDS Plc) for supporting this study by making available the dp-ucMGP assay. This study was a part of a habilitation thesis [Kurnatowska I. Medical University, Łódź 2013]. This study was partially supported by the Medical University of Lodz grant No. 503/1-151-02/503-01 and was registered in ClinicalTrials.gov Identifier: NCT01101698.

\section{References}

1 Cranenburg EC, Schurgers LJ, Vermeer C: Vitamin K: the coagulation vitamin that became omnipotent. Thromb Haemost 2007;98:120-125.

2 Holden RM, Morton AR, Garland JS, Pavlov A, Day AG, Booth SL: Vitamins K and D status in stages 3-5 chronic kidney disease. Clin J Am Soc Nephrol 2010;5:590-597.

3 Keith DS, Nichols GA, Gullion CM, Brown JB, Smith DH: Longitudinal follow-up and outcomes among a population with chronic kidney disease in a large managed care organization. Arch Intern Med 2004;164:659-663.

4 Garg AX, Clark WF, Haynes RB, House AA: Moderate renal insufficiency and the risk of cardiovascular mortality: results from the NHANES I. Kidney Int 2002;61:1486-1494.

5 Beulens JW, Bots ML, Atsma F, Bartelink ML, Prokop M, Geleijnse JM, Witteman JC, Grobbee DE, van der Schouw YT: High dietary menaquinone intake is associated with reduced coronary calcification. Atherosclerosis 2009;203:489-493.

6 Geleijnse JM, Vermeer C, Grobbee DE, Schurgers LJ, Knapen MH, van der Meer IM, Hofman A, Witteman JC: Dietary intake of menaquinone is associated with a reduced risk of coronary heart disease: the Rotterdam Study. J Nutr 2004;134:3100-3105.

7 Kurnatowska I, Grzelak P, Masajtis-Zagajewska A, Kaczmarska M, Stefańczyk L, Vermeer C, Maresz K, Nowicki M: Effect of vitamin K2 on progression of atherosclerosis and vascular calcification in nondialyzed patients with chronic kidney disease stage 3-5. Pol Arch Med Wewn 2015;125:631-640.

8 Knapen MH, Braam LA, Drummen NE, Bekers O, Hoeks AP, Vermeer C: Menaquinone-7 supplementation improves arterial stiffness in healthy postmenopausal women. A double-blind randomised clinical trial. Thromb Haemost 2015;113:1135-1144.

9 Thijssen HH, Drittij-Reijnders MJ: Vitamin K status in human tissues: tissue-specific accumulation of phylloquinone and menaquinone. Br J Nutr 1996;75:121-127.

10 Shanahan CM, Proudfoot D, Farzaneh-Far A, Weissberg PL: The role of Gla proteins in vascular calcification. Crit Rev Eukaryot Gene Expr 1998;8:357-375. 


\section{Kidney \\ Blood Pressure Research}

Kidney Blood Press Res 2016;41:231-239

DOI: $10.1159 / 000443426$

Published online: April 21, 2016

(C) 2016 The Author(s). Published by S. Karger AG, Base www.karger.com/kbr

11 Schurgers LJ, Teunissen KJ, Knapen MH, Kwaijtaal M, van Diest R, Appels A, Reutelingsperger CP, Cleutjens JP, Vermeer C: Novel conformation-specific antibodies against matrix gamma-carboxyglutamic acid (Gla) protein: undercarboxylated matrix Gla protein as a marker for vascular calcification. Arterioscler Thromb Vasc Biol 2005;25:1629-1633.

12 Schurgers LJ, Spronk HM, Soute BA, Schiffers PM, DeMey JG, Vermeer C: Regression of warfarin-induced medial elastocalcinosis by high intake of vitamin K in rats. Blood 2007;109:2823-2831.

13 Cranenburg EC, Koos R, Schurgers LJ, Magdeleyns EJ, Schoonbrood TH, Landewé RB, Brandenburg VM, Bekers 0 , Vermeer C: Characterisation and potential diagnostic value of circulating matrix Gla protein (MGP) species. Thromb Haemost 2010;104:811-822.

14 Rennenberg RJ, de Leeuw PW, Kessels AG, Schurgers LJ, Vermeer C, van Engelshoven JM, Kemerink GJ, Kroon AA: Calcium scores and matrix Gla protein levels: association with vitamin K status. Eur J Clin Invest 2010;40:344-349.

15 Cranenburg EC, Schurgers LJ, Uiterwijk HH, Beulens JW, Dalmeijer GW, Westerhuis R, Magdeleyns EJ, Herfs M, Vermeer C, Laverman GD: Vitamin K intake and status are low in hemodialysis patients. Kidney Int 2012;82:605-610.

16 Westenfeld R, Krueger T, Schlieper G, Cranenburg EC, Magdeleyns EJ, Heidenreich S, Holzmann S, Vermeer C, Jahnen-Dechent W, Ketteler M, Floege J, Schurgers LJ: Effect of vitamin K2 supplementation on functional vitamin K deficiency in hemodialysis patients: a randomized trial. Am J Kidney Dis 2012;59:186-195.

17 Schurgers LJ, Barreto DV, Barreto FC, Liabeuf S, Renard C, Magdeleyns EJ, Vermeer C, Choukroun G, Massy ZA: The circulating inactive form of matrix gla protein is a surrogate marker for vascular calcification in chronic kidney disease: a preliminary report. Clin J Am Soc Nephrol 2010;5:568-575.

18 Beulens JW, Booth SL, van den Heuvel EG, Stoecklin E, Baka A, Vermeer C: The role of menaquinones (vitaminK2) in human health. Br J Nutr 2013;110:1357-1368.

19 Dalmeijer GW, van der Schouw YT, Vermeer C, Magdeleyns EJ, Schurgers LJ, Beulens JW: Circulating matrix Gla protein is associated with coronary artery calcification and vitamin K status in healthy women. J Nutr Biochem 2013;24:624-628.

20 Dalmeijer GW, van der Schouw YT, Magdeleyns E, Ahmed N, Vermeer C, Beulens JW: The effect of menaquinone-7 supplementation on circulating species of matrix Gla protein. Atherosclerosis 2012;225:397-402.

21 Dam V, Dalmeijer GW, Vermeer C, Drummen N E, Knapen MH, van der Schouw YT, Beulens JW: Association Between Vitamin K and the Metabolic Syndrome: A 10-Year Follow-Up Study in Adults. J Clin Endocrinol Metab 2015;100:2472-2479.

22 Caluwé R, Vandecasteele S, Van Vlem B, Vermeer C, De Vriese AS: Vitamin K2 supplementation in haemodialysis patients: a randomized dose-finding study. Nephrol Dial Transplant 2014;29:1385-1390.

23 Delanaye P, Krzesinski JM, Warling X, Moonen M, Smelten N, Médart L, Pottel H, Cavalier E: Dephosphorylated-uncarboxylated Matrix Gla protein concentration is predictive of vitamin $\mathrm{K}$ status and is correlated with vascular calcification in a cohort of hemodialysis patients. BMC Nephrol 2014;15:1-8.

24 Kidney Disease: Improving Global Outcomes (KDIGO) CKD Work Group. KDIGO 2012 clinical practice guideline for the evaluation and management of chronic kidney disease. Kidney Int Supp 2013;3:1-150.

25 Boxma PY, van den Berg E, Geleijnse JM, Laverman GD, Schurgers LJ, Vermeer C, Kema IP, Muskiet FA, Navis G, Bakker SJ, de Borst MH: Vitamin k intake and plasma desphospho-uncarboxylated matrix Gla-protein levels in kidney transplant recipients. PLoS One 2012;7:1-8.

26 Gopalakrishnan R, Ouyang H, Somerman MJ, McCauley LK, Franceschi RT: Matrix gammacarboxyglutamic acid protein is a key regulator of PTH-mediated inhibition of mineralization in MC3T3-E1 osteoblast-like cells. Endocrinology 2001;142:4379-4388.

27 Suttamanatwong S, Jensen ED, Schilling J, Franceschi RT, Carlson AE, Mansky KC, Gopalakrishnan R: Sp proteins and Runx2 mediate regulation of matrix gla protein (MGP) expression by parathyroid hormone. J Cell Biochem 2009;107:284-292.

28 Staude H, Jeske S,Schmitz K, Warncke G, Fischer DC: Cardiovascular Risk and Mineral Bone Disorder in Patients with Chronic Kidney Disease. Kidney Blood Press Res 2013;37:68-83.

29 Nagasawa Y, Fujii M, Kajimoto Y, Imai E, Hori M: Vitamin K2 and serum cholesterol in patients on continuous ambulatory peritoneal dialysis. Lancet 1998;351:724. 